This manuscript has been submitted for publication in the Journal of Geoscience Education. Please note that, despite being peer-reviewed, the manuscript has yet to be formally accepted for publication. Subsequent versions of this manuscript may have slightly different content. If accepted, the final version of this manuscript will be available via the 'Peer-reviewed Publication DOI' link on the right-hand side of this webpage. Please feel free to contact any of the authors; we welcome feedback. 


\title{
Mirroring minoritized students' cultures in Geoscience courses
}

\author{
Vanshan Wright $^{1 *}$ and Alissa J. Kotowski ${ }^{2 \dagger}$ \\ ${ }^{1}$ Woods Hole Oceanographic Institution, Geology and Geophysics, Woods Hole, MA \\ ${ }^{2}$ The University of Texas at Austin, Jackson School of Geosciences, Austin, TX \\ Both authors contributed equally to this work.
}
*Now at University of California San Diego, Scripps Institution of Oceanography, San Diego, CA
$\dagger$ Now at McGill University, Dept. of Earth and Planetary Sciences, Montreal, Quebec, Canada
Corresponding author: Vanshan Wright, vwright@ucsd.edu
Corresponding author: Alissa Kotowski, alissa.kotowski@ mcgill.ca




\section{ABSTRACT}

The use of active-learning strategies to teach out-of-school time (OST) geoscience courses has not significantly increased the number of racially minoritized students that pursue Geoscience. Studies hypothesize that significantly more minoritized students would pursue Geoscience if courses better resemble the students' Collectivist cultures. We test this hypothesis by using pre-course, post-course, and after-activity surveys to quantify minoritized student engagement, perception of, and interest in pursuing Geoscience during two OST courses taught with learning activities that emphasize Individualism (individual-learning) or Collectivism (group-learning). After-activity surveys show that minoritized students $(n=68)$ prefer grouplearning activities. Students rated group activities as more difficult and fun. Students also believed they learned more during group-learning activities. Their engagement and interest in lessons varied more widely during individual-learning activities. Pre- and post-course surveys reveal that the number of students interested in pursuing STEM and Geoscience increased from 43 to 54 and 11 to 16 , respectively. The students' perceptions of geoscientists broadened to include scientists who study not only the Earth but also its history and governing processes. We interpret these results to mean that (1) educators may employ group-learning activities when they desire to increase task difficulty without sacrificing student engagement, and (2) individuallearning activities are less reliable means of engaging minoritized students. Our results imply that incorporating more group-learning activities in the classroom and field may improve Geoscience diversity since group-learning activities resonate more strongly with minoritized students' cultures. 


\section{I INTRODUCTION}

2 Out-of-school time (OST) Geoscience courses have been locally successful at increasing

3 the likelihood that minoritized students pursue STEM and Geoscience college degrees (Baber et

4 al., 2010; Carrick et al., 2016; Wechsler et al., 2005). Researchers attribute these programs'

5 successes to increased Geoscience visibility as a career choice, direct mentorship, and hands-on

6 research experiences during formative years (e.g., Huntoon \& Lane, 2007; Levine et al., 2007).

7 Despite the local successes of some OST, a significant number of programs experience

8 stagnation or limited success that prevent community-wide improvements in Geoscience

9 diversity (Sidder, 2017). The reasons for the lack of larger-scale success are unclear but could be

10 due to several intersecting factors. These include but are not limited to perceived disconnects

11 Geoscience and marginalized communities' cultures, racism and microaggressions experienced

12 by minoritized students in academia, marginalized communities' less favorable views of

13 Geoscience compared to other careers (e.g., health sciences and engineering), a leaky pipeline,

14 and prolonged lag-time between pre-college exposure and entry into professional Geoscience

15 careers (Levine et al., 2007; Riggs \& Alexander, 2007). This study’s key goals are to explore the

16 roles of pedagogy and culture on increasing recruitment of minoritized high school students.

17 Understanding how this and other factors affect recruiting and retaining minoritized students is

18 imperative since Geoscience remains one of the least ethnically and racially diverse STEM

19 disciplines (Bernard \& Cooperdock, 2018; Huntoon \& Lane, 2007).

20 Typical Geoscience pedagogical techniques appear to resonate less with minoritized

21 students' cultures, which could negatively impact students' experiences and perceptions of

22 Geosciences (cf. Callahan et al., 2017; Weissmann et al., 2019; Wolfe \& Riggs, 2017).

23 Traditionally, Geoscience instructors mostly lecture and assess students via quizzes and tests. 
24 These pedagogical techniques favor students from individualistic cultures, defined as cultures

25 that emphasize individuated, linear, and faculty-oriented hierarchical perspectives of learning

26 (Hall, 1989; Ibarra, 1999, 2001). Minoritized students more often grow up in collectivist

27 cultures, which emphasize process-oriented and systems thinking, that individual efforts are not

28 primarily for self-interest but for the success of the entire group, and which embody a desire to

29 improve the community and/or society as a whole (Chavez \& Longerbeam, 2016). Collectivist

30 pedagogy thus emphasizes learning activities that require teamwork, group harmony, and

31 emotional connection for success. The disconnect between minoritized students' cultures and

32 individualistic academic culture may weaken minoritized students' sense of belonging and self-

33 efficacy during science learning (e.g., Baber et al., 2010; Johnson et al., 2007), which are known

34 to contribute to the leaky Geoscience pipeline (cf. Levine et al., 2007). An open question is

35 whether transitioning from an Individualistic to Collectivist pedagogical model would increase

36 minority student engagement and enthusiasm for Geoscience (cf. Weissmann et al., 2019; Wolfe

37 \& Riggs, 2017).

38 This pilot study tests the hypothesis that transitioning from traditional, Individualist

39 learning to Collectivist learning in OST field- and classroom-based Geoscience courses increases

40 minoritized students' engagement and interest in pursuing Geoscience. Our pedagogical reform

41 draws from Astin's (1984) Inputs-Environment- Output (I-E-O) model, which posits that student

42 Inputs (e.g., cultural upbringing, personal preferences, and tendencies) combined with a specific

43 'interventions' and/or Environments (e.g., an OST pre-college course) can produce desired

44 outcomes (e.g., changes in career aspirations, perception of and/or interest in pursuing

45 Geoscience). We used I-E-O to restructure two existing OST courses within the GeoFORCE

46 Texas program and administered pre-course, post-course, and activity-specific surveys to test our 
47 hypothesis. Our qualitative and quantitative results show that minoritized students prefer group

48 over individual-learning activities, group-learning activities are more reliable at engaging

49 minoritized students, and difficult activities become more engaging when done in groups. Thus,

50 our pilot study reveals a potential connection between students' cultures and self-assessed

51 learning preferences, understanding, and interest in Geoscience. Ultimately, this is one small

52 example of how pedagogical reform may contribute to diversifying Geoscience.

\section{2 BACKGROUND}

GeoFORCE has taught Geoscience to $~ 1800$ Central and Southwest Texas students

55 through week-long summer field-based courses since 2005. One of GeoFORCE's primary goals

56 is to increase the number of minoritized students that enter Geosciences. Students enter

57 GeoFORCE's program as rising high school freshmen and take GeoFORCE courses during the

58 summer before each new school year. Even though GeoFORCE has increased the number of

59 students pursuing STEM college degrees (e.g., 51\% of college-enrolled alumni were STEM

60 majors in 2017; GeoFORCE, 2017), the percentage of students pursuing Geoscience degrees has

61 remained relatively low (e.g., $10 \%$ of STEM-enrolled students in 2017; compare with $14 \%$

62 enrolled in Biology; GeoFORCE, 2017). Our goal is to assess whether disconnects between the

63 Geoscience pedagogy and minoritized students' culture could be related to why relatively few

64 GeoFORCE students enter Geosciences.

Even though field-based courses are generally effective means of learning (Boyle et al.,

66 2007; Elkins \& Elkins, 2007), minoritized students could be deterred by the outdoor component

67 of Geoscience learning since they are less likely than their white peers to report enjoyment of

68 outdoor activities like hiking and camping (Whitney et al., 2005). Minoritized students are also

69 more likely to negatively associate outdoor work with laboring (Seymour \& Hewitt, 1997). This 
70 scenario illustrates the influence of cultural values and socialization as components of the

71 'Geoscience Pipeline' (Levine et al., 2007) that influence the likelihood of minoritized students

72 entering and staying in Geoscience professions (cf. Seymour \& Hewitt, 1997).

73 Researchers suggest two strategies for reducing the disconnect between minoritized

74 student culture and learning environment. Firstly, as opposed to traditional lecturing and quiz-

75 and-test assessment, active-learning strategies have been shown to significantly improve

76 retention and engagement and deepen STEM interest for minoritized students (Graham et al.,

77 2013; Sherman-Morris \& McNeal, 2016; Tsui, 2007). Secondly, several previous OST courses

78 have had great success engaging minoritized students by teaching in a culturally-situated context,

79 thus making Geoscience more relevant, relatable, and inclusive for minoritized learners (Apple et

80 al., 2014; Brown et al., 1989; Riggs \& Alexander, 2007; Unsworth et al., 2012). For example,

81 Semken (2005) demonstrated that Place-Based Learning, which synthesizes local cultural

82 knowledge, builds student confidence in 'thinking like a geoscientist' and makes it easier for

83 students to see themselves as professional Geoscientists (see also Hanks et al., 2007; Pandya et

84 al., 2007). Furthermore, Tewksbury (1995) taught an introductory-level, classroom-based

85 geology class on modern Africa, connecting its geology to its prehistoric, historical, political,

86 and economic evolution. This course enrolled 11 African American students, which represented

87 more than one-sixth of her university's African American enrollment at the time. Thus, active

88 learning and culturally-situated learning positively impact minoritized student learning. This lead

89 us to hypothesize that blending both strategies would positively impact minoritized student

90 learning, engagement, and interest in STEM.

913 STUDY PARTICIPANTS 
Our study population includes sixty-five rising eleventh (40 students) and twelfth-grade

93 (25 students) students in two of GeoFORCE's OST courses. All students live in underserved

94 communities and/or attend minority-majority high schools in Texas. The students are 56\%

95 women, 44\% Black or African American, 12\% Asian or Pacific Islander, 36\% Hispanic or

96 Latinx, and $8 \%$ white. Fifty-six percent of these students have at least one parent with a four-year

97 college degree. Ninety-six percent of the students previously took a science course taught using

98 active-learning pedagogy (Fig. 1).

99 Educational and coordination staff facilitated student learning. Educational staff (3-5

100 individuals) included (1) an instructor who was responsible for course content, design, and

101 pedagogy and (2) two educational coaches (ECs) who primarily assist with pedagogy. The

102 twelfth-grade academy also employed two teaching assistants named Educational Coaches in

103 Training (ECITs). Instructor-to-student ratios were 1:13 and 1:5 in the eleventh and twelfth-

104 grade academies, respectively. Two coordination staff members executed field trips and

105 classroom logistics; one person obtained supplies.

106 The educational and coordination staff reflected the students' racial and ethnic diversity.

107 The course instructors are the authors of this paper and were late-career Ph.D. students when

108 they taught the courses. The eleventh-grade instructor is a white woman and a Structural

109 Geology Postdoctoral Researcher. The twelfth-grade instructor is a black man and Geophysics

110 Postdoctoral Investigator. The eleventh-grade academy ECs were one Geocognition (white male)

111 and one Geology (multi-ethnic Hispanic-American male) Ph.D. student. The twelfth-grade

112 academy ECs were a mid-career high school science teacher (Latina) and a Geology Ph.D.

113 student (Asian-American woman); the ECITs were two undergraduate STEM pre-service 
114 teachers (a Latina and a black woman). The coordinators were the same for both academies, one

115 Latino and one white woman.

\section{RESEARCH DESIGN AND METHODS}

117 We used pre-trip and post-trip surveys to assess student learning preferences and interest

118 in lessons taught with active-learning strategies that emphasize Individualism or Collectivism.

119 We used after-activity surveys to evaluate the students' engagement (i.e., fun and excitement),

120 interest in, and perception (i.e., difficulty and understanding) of the learning activities and

121 Geoscience. We statistically analyze the surveys with means, standard deviations, correlation

122 coefficients, and T-tests. We conducted this research with Institutional Review Board approval

123 from the University of Texas at Austin.

\section{$124 \quad 4.1$ Course Design and Structure}

125 We categorized learning activities as individualistic, intermediate, and collectivist,

126 rated from 1 to 10 , where 1 is extremely individual, and 10 is extremely collectivist.

127 Individualistic learning activities included lecturing, single-person active-learning activities (e.g.,

128 concept sketching), and quizzes. Intermediate activities included workshops -- i.e., guided

129 inquiry, hands-on, group activities that access affective learning domains and stimulate critical

130 thinking through skill-building. Intermediate activities introduced new concepts and themes and

131 were a mixture of student-driven and instructor-guided learning. Collectivist activities included

132 societally relevant challenge-based field tasks that apply critical thinking skills and content

133 learned during workshops and/or synthesis projects that take 3-5 days to solve and emphasize

134 teamwork. Collectivist activity problem-solving was dominantly student-driven.

135 4.1.1 Eleventh-grade Pacific Northwest Academy 
The eleventh-grade academy taught students Plate Tectonics, earthquake and volcano

137 hazards, and the formation of modern sedimentary depositional environments in Oregon and

138 Washington. Previous GeoFORCE students who completed four years of lecture-based, quiz-

139 and-test assessment (i.e., traditional) Academies reported that the Pacific Northwest Academy

140 was their favorite because of the beautiful landscapes and volcanoes. Instructors taught this

141 cohort's course using a "slow-release" active-learning strategy (Fig. 2A). Most activities during

142 the first three days included "individualist" lecturing and "intermediate" workshops. The

143 activities became more "collectivist" and more difficult during days 4-6. "Individualist" and

144 "intermediate" activities prepared students for the more challenging "collectivist" activities.

145 Eleventh-grade instructors taught most of the course using classroom- and field-based

146 guided inquiry, in which instructors chose topics and questions and students designed products

147 and solutions. For example, during one series of workshops, students drew concept sketches of

148 volcanoes while instructors guided them through discussion of similarities and differences in

149 formations and functions between 'end-member' volcanoes; students identified minerals and

150 igneous rocks; and students performed experiments to learn about viscosity using 'lavas' of

151 different 'compositions' (e.g., water, olive oil, honey, mayonnaise). Students then used their

152 knowledge in the field, where instructors tasked them with reconstructing how quickly a Cascade

153 porphyritic andesite from Mount Hood cooled, what the magma's composition was that formed

154 the rocks, and how explosive the eruption likely was. The eleventh-grade course also

155 incorporated one multi-day (days 4-6) activity where teams of 5-6 students conducted synthesis

156 projects related to "The Rock Cycle" or "Natural Hazards." The form and medium of the

157 synthesis project were left entirely up to the students; products included an anthropomorphized 
158 skit of the rock cycle, hand-drawn annotated and narrated videos (e.g., "Moovly" or "Whiteboard

159 Animations"), and a news broadcast complete with interviews with "local geology experts."

\subsubsection{Twelfth-grade Central Texas Academy}

The twelfth-grade academy taught students the geologic history of Central Texas while

162 emphasizing the effects of tectonism, volcanism, erosion, water, and biological life on landscape

163 evolution. Instructors taught using the STAR Legacy Cycle (Bransford, 2017), following a

164 curriculum developed specifically for the GeoFORCE twelfth-grade academy (Ellins et al., 2018;

165 Thomas et al., 2018; Kotowski et al., 2018). The Legacy Cycle includes six learning stages

166 referred to as (1) the challenge, (2) generating ideas, (3) gaining multiple perspectives, (4)

167 researching and revising, (5) assessing, and (6) going public (Fig. 2B). Twelfth-grade instructors

168 taught each Legacy Cycle stage using hands-on active learning workshops, lectures, and guided

169 inquiry field activities. During the challenge stage, instructors presented students groups with a

170 practical (i.e., real-life applicable) problem to solve -- i.e., (1) designed Snapchat filters to entice

171 18-to-34-year-olds to visit and learn the geologic history of six Central Texas national parks or

172 (2) conducted background geologic work for Google Sustainability who wants to evaluate the

173 impacts of human development on landscape and water resources in Central Texas before

174 building a new Google campus in Austin. The generating ideas stage is where instructors

175 provided the background information needed to accomplish the challenge. The gaining multiple

176 perspectives stage is where instructors introduced students to external resources and technology

177 to supplement learning. Students designed the methods required to solve the challenge during the

178 research and revise stage. Students collected new data, made independent observations, and drew

179 interpretations during the three stages described above. The instructional staff facilitated this by

180 fielding questions, redirecting off-topic efforts, and correcting student mistakes through group 
181 discussions. In the assessment stage, students tested their designed methods. Students presented

182 their work to an audience of fellow students, educational and coordination staff, invited experts,

183 and the general public during the going public stage. Students generally progressed through each

184 successive stage of the cycle with time (e.g., day 1-7). Earlier stages were revisited as instructors

185 and students deemed necessary; the larger cycle thus contains smaller, embedded cycles of active

186 learning (Fig. 2B).

\section{$187 \quad 4.2$ Survey Types and Assessment Strategies}

We announced the research goals before administering the pre-course, post-course, and

189 after-activity surveys (see Table 1). Student survey participation was optional, and responses

190 were anonymous. The total number of pre- and post-survey responses are not the same (eleventh

191 grade: 40 pre, 35 post; twelfth grade: 25 pre, 22 post) because some students did not respond to

192 the post-course survey.

193 Pre- and post-course surveys solicited student demographic data, life experiences,

194 learning preferences, previous academic backgrounds, career aspirations, and perceptions of

195 science and Geoscience. The surveys requested free-form, Likert-scaled, and/or multiple-choice

196 answers. Students filled out the pre- and post-course surveys on the first day and within 1-2 days

197 after the courses ended, respectively. Both surveys asked the same questions.

198 The after-activity surveys assess student engagement and interest during learning-

199 activities. These surveys solicit free responses to "the main thing I had to do today was" and ask

200 students to rate (from 1 to 10 ) their interest in learning more about a topic, how well they

201 believed they understood topics, and how difficult, exciting, and fun topics were. Students

202 mainly completed these surveys within 24 hours after each activity, either while traveling, in

203 classrooms, or at the end of the day. We designed these surveys to be completed in five minutes. 
We used pre-course, post-course, and activity-specific surveys to assess changes to the

205 students' (1) perception of science and Geoscience, (2) interest in pursuing STEM and

206 Geoscience, and (3) preference for individual versus group activities. We calculated means and

207 standard deviations for Likert-scaled answers. We used Welch's T-test to determine whether

208 there were statistically significant changes in responses to the pre- and post-course survey

209 questions. We denote p-value, t-statistics, and degrees of freedom from the T-tests with

210 acronyms $p, t$, and $d f$, respectively. We performed correlation coefficient analyses between all

211 variables and used indexing and qualitative description analysis (QDA) to identify commonly

212 used descriptors and themes within free response answers (cf. Libarkin \& Kurdziel, 2002).

\section{RESULTS}

214 Survey data demonstrate that the students prefer learning in groups, regardless of the

215 tasks' difficulties. Results from both academies are mostly similar. We combine and present the

216 survey data together, and we highlight notable differences.

\section{$217 \quad 5.1$ Student learning preferences}

218 Pre- and post-course surveys reveal that the course influenced the students' preferences

219 for group, hands-on, and individual-learning. Students' preference for individual learning

220 decreased $(p=0.0025, t=3.10, d f=97.80)$ while their preference for group learning slightly

221 increased $(p=0.34, t=-1.00, d f=117.00)$. The students' confidence in public speaking and how

222 much they like lectures increased $(p=0.0006, t=-3.52, d f=117.99$ and $p=0.008, t=-2.70, d f$

$223=118.29$, respectively) (Fig. 3A). Student preference for hands-on activities and group projects

224 was roughly the same in pre- and post-course surveys (i.e., $\sim 8 / 10)(p=0.58, t=0.56, d f=115.50$

225 and $p=0.68, t=0.42, d f=11.38$, respectively). The students' free-form answers revealed that

226 they believed group workshops prepared them relatively well for field activities. 


\subsection{Student engagement during individual- vs. group-learning activities}

Students felt they learn more as the lessons become more exciting, fun, and interesting.

229 High positive correlations $\left(\mathrm{r}^{2}>0.7\right)$ exist between (1) the students' interest in learning more

230 about a topic and their perception of how much fun they had learned and (2) how fun and

231 exciting they thought topics were (Fig. 3B). Moderate positive correlations $\left(\mathrm{r}^{2}=0.5-0.6\right)$ exist

232 between (1) interest in learning more about topics and how exciting they believe topics were, and

233 (2) how much fun they thought they had and their interest in learning more about topics (Fig.

234 3B). A low positive correlation $\left(\mathrm{r}^{2}<0.4\right)$ exists between interest in learning more about a topic

235 and the students' perceived understanding. The students' perception of the difficulty of learning

236 activities moderately anti-correlates their interest in learning more about the topics (Fig. 3B). No

237 significant correlation exists between the students' perceived difficulty of learning activities and

238 how much fun students believed the activities were. In general, correlations between students'

239 perceived understanding, interest, fun, and excitement are stronger for group versus individual-

240 learning activities.

\subsection{Evolution of students' perception of Geoscience and career aspirations}

242 Indexing and QDA of student responses provide insights into the students' view of

243 scientists and Geoscience careers. Student responses to 'describe a scientist in three words'

244 demonstrate that students primarily believe that scientists are smart, intelligent, curious, hard-

245 working, and creative. Problem-solve, discover, and study were the students' three most

246 commonly used verbs to describe what scientists do. The frequency of mentions of these three

247 words was roughly the same in pre- and post-surveys (see appendix A). While describing a

248 Geoscientist's job, students' use of 'process' increased from one to seven times in pre- and post-

249 surveys, respectively (Table 2). Other used process-oriented verbs and descriptors include 
250 'function,' 'Earth's history and its formation', and 'how landforms are shaped.' The number of

251 students mentioning 'rocks' on pre- and post-course surveys was 24 versus 11, respectively. The

252 percentage of students indicating that they will pursue a non-geoscience STEM major and

253 Geoscience in college before and after the course increased from 69 to $93 \%$ and 15 to $27 \%$,

254 respectively (Fig. 5). The number of students interested in pursuing Geoscience rose from 4 to 10

255 and from 2 to 4 in the eleventh and twelfth-grade courses, respectively.

2566 DISCUSSION AND IMPLICATIONS

257 Our primary interpretations are that (1) students prefer collectivist active-learning

258 activities and (2) culturally-situated pedagogical approaches may improve Geoscience diversity.

259 Our sample size is relatively small (65 students). Additional studies are thus needed to test the

260 robustness of these findings.

261 6.1 Students prefer active learning that emphasizes Collectivism

262 Students prefer active-learning activities that emphasize Collectivism. This is supported

263 by the observations that students consistently (1) rated active group-learning exercises as the

264 most exciting, interesting, and fun activities (cf. Fig. 3B) and (2) remained more engaged (e.g.,

265 excited, interested, and had more fun) during the most difficult active-learning group activities

266 (cf. Fig. 3B, see colored circles in 'difficulty vs. interest' and 'fun vs. difficulty'). We also

267 interpret that active-learning group activities are more reliable at engaging students because the

268 standard deviations for moderate and strong correlations in group-activity data are smaller than

269 in individual active-learning activities.

270 Since our active learning exercises were completed in student groups and were presented

271 as challenges with societal relevance, this work suggests that active learning impacts may be

272 amplified when executed in a culturally-situated framework (cf. Lee \& Fradd, 1998). This 
273 inference is supported by observations that group activities show moderate positive correlations

274 between engagement metrics (e.g., interest, excitement, and fun) and perceived understanding.

275 Thus, instructors can increase tasks' difficulty without sacrificing engagement or their perceived

276 understanding when students work in groups. The students' strong preference for hands-on

277 workshops and group-learning demonstrates that more difficult group activities are no less

278 engaging or challenging to understand according to students' perception of their own learning

279 compared to individual activities that may seem easier to do. Active learning has been suggested

280 as a useful tactic to improve recruitment and combat attrition of minoritized students in STEM

281 disciplines (Graham et al., 2013; Tsui, 2007); we suggest that the intersection of active and

282 culturally-situated learning may amplify the positive impacts of both strategies (e.g., Fig. 6).

\section{6.2 Can culturally-situated group-learning improve Geoscience diversity?}

284 Our study suggests that mirroring minoritized students' cultures in Geoscience courses

285 can improve student engagement, broaden their perceptions of Geoscience, and increase their

286 interest in pursuing STEM and Geoscience in college. Comparing pre- and post-survey free

287 responses of a geoscientist's job description, the increased occurrence of process-oriented terms

288 and decreased occurrence of the narrowed view that a geoscientist "studies rocks" is particularly

289 noteworthy. The changes to the students' perception of scientists and geoscientists likely occur

290 for several reasons. Chief amongst them are subject matter, hands-on activities, group-learning

291 projects, and what the instructors emphasize during the courses. However, both GeoFORCE

292 cohorts exhibited similar perception changes, despite focusing on very different topics and

293 themes. Therefore, we tentatively rule out the possibility that specific course content led to a

294 more process-oriented view. The focus on a process-oriented view of Geoscience aligns with

295 aspects of high-context, Collectivist cultural ideals (Chavez \& Longerbeam, 2016; Ibarra, 1999), 
296 which we interpret to be the most likely cause of the increased interest and broadening of 297 students' perspective.

298 The increase in the number of students who want to pursue STEM, and Geoscience 299 specifically, is a significant improvement compared to GeoFORCE statistics as a whole. Before 300 implementing the Legacy Cycle model with the twelfth-grade academies in 2018, all

301 GeoFORCE courses were taught using a traditional, lecture-based, and quiz-and-test-assessment 302 approach. For a rough comparison, in 2017, 51\% of all college-enrolled GeoFORCE alumni 303 were STEM majors, and of that sub-group, 10\% had declared Geoscience majors (GeoFORCE, 304 2017). Compare these percentages with our small study population, which reported increased 305 interest in pursuing STEM, up from $69 \%$ (pre) to 93\% (post), and Geoscience, up from 15\% 306 (pre) to $27 \%$ (post). The only programmatic difference between our study population's 307 experience and previous GeoFORCE students' is our pedagogy. Therefore, we attribute these 308 evolutions to our culturally-situated pedagogical shift.

309 The call to rebuild OST pedagogical foundations for programs like GeoFORCE around 310 student identities, cultures, and worldviews is supported by recent research addressing the 311 sociological, psychological, and socio-economic 'whys' that can explain some diversity 312 programs' successes (cf. Callahan et al., 2017; Riggs \& Alexander, 2007; Lave and Wenger, 313 1991; Weissmann et al., 2019; Wolfe \& Riggs, 2017). Furthermore, previous efforts to 314 incorporate culturally-situated teaching have had noteworthy success and promise to improve 315 community diversity. For example, Semken (2005) demonstrated that Place-Based Learning that 316 synthesizes local cultural knowledge builds student confidence in 'thinking like a geoscientist,' 317 making it easier for students to potentially see themselves filling professional Geoscience roles 318 (see also Hanks et al., 2007; Pandya et al., 2007; Tewksbury, 1995). Furthermore, culturally- 
319 situated learning can increase students' sense of belonging (Moore, 2020), which is yet another

320 'valve' along the Geoscience pipeline. Our study thus lends credence to previous work that

321 highlights the benefits of deemphasizing Individualism and Western academic linearity and

322 competition, in favor of group and community membership, the interconnectedness of scientific

323 cycles and processes, teamwork, and practical problem-solving for community betterment

324 (Seymour \& Hewitt, 1997; Weissmann et al., 2019; Wolfe \& Riggs, 2017). As educators, we can

325 take small steps in our field- and classroom-based courses towards a systemic climatic shift that

326 better resonates with our minoritized students' cultural values. Our small-scale study serves as

327 motivation for more extensive (in regards to the number of participants) and targeted (in

328 development of culturally-situated activities and survey questions) studies addressing how to

329 best employ culturally-situated learning tools to improve Geoscience diversity.

$330 \quad 6.3$ Limitations of the present study and future research directions

331 Our study's primary assumption is that the students, being $>50 \%$ women and $>50 \%$

332 Hispanic, Latinx, and Black, identify with Collectivist cultures. We make this assumption

333 because research shows that women and ethnically and racially minoritized students primarily

334 identify with Collectivist cultural ideals (Chavez \& Longerbeam, 2016; Ibarra, 1999, 2001). The

335 students within this study likely embody a spectrum of cultural beliefs and life experiences that

336 expand beyond Collectivism (cf. Gudykunst et al., 1996). However, our pre- and post-survey

337 data support that, on average, these students prefer learning styles that are group-focused and

338 societally-relevant. Therefore, the assumption that these students identify more with Collectivism

339 is likely valid for this pilot study. Further research is needed to characterize the relationship

340 between student cultural identity and learning preferences. In reality, a Multicontext and/or 
341 blended approach will likely produce the most effective, engaging, and inclusive learning

342 environment (e.g., Weissmann et al., 2019; Fig. 6).

343 Our study does not have a control group because COVID-19 is real and prevents

344 additional in-person work. One way to introduce a control group is to distribute identical pre-,

345 post-, and activity-specific surveys to separate cohorts that experience the traditional versus

346 culturally-situated approach in the same field location; the sane educational team should teach

347 the courses. Control groups will be crucial in defining what aspects of the GeoFORCE

348 'intervention,' i.e., the 'Environmental' aspect of the I-E-O model, are controlling Outputs (i.e.,

349 changes in student perception and engagement) (Astin, 1991).

$350 \quad$ Field locations may influence student engagement and enthusiasm in ways that we did

351 not quantify. Since many GeoFORCE alumni report that the eleventh-grade Pacific Northwest

352 trip to be their favorite, the greater increase in reported interest in pursuing Geoscience in

353 eleventh-grade students may reflect this partially. However, student interviews from past

354 academies suggest a common motivation to participate in GeoFORCE is to apply acquired

355 knowledge and skills to understand Earth in 'their own backyards.' This indicates that a

356 connection to place may elevate student experience in the twelfth-grade academy (Hanks et al.,

357 2007; Semken, 2005; Semken et al., 2017). Lack of substantial differences in the evolution of

358 student learning preferences supports our interpretation that changes in student learning

359 preferences and perception of Geosciences arose mainly from the pedagogical shift, not just

360 because students were exposed to new and exciting places (e.g., the Pacific Northwest). Future

361 targeted evaluations assessing the impact of course location should nevertheless be conducted to

362 determine the influence of connection to place and other external factors on minoritized student

363 interest in the Geosciences. 
This study assesses whether racially minoritized students become more engaged and

366 interested in pursuing Geoscience when instructors teach in ways that resemble these students'

367 cultures more closely. Pre-course, post-course, and after-activity surveys reveal that minoritized

368 students within two (one eleventh- and one twelfth-grade) academies in GeoFORCE's out-of-

369 school-time program become more engaged during active-learning activities that emphasize

370 hands-on and group-learning versus individual-learning activities. By the end of the courses,

371 students' perception of Geoscientists broadened from someone who studies not only the Earth

372 but also its governing processes. This broadening of student perception is likely related to the

373 students' exposure to diverse people, technology, resources, and problem-solving methods

374 during the courses. The number of students considering majoring in Geoscience in college

375 increased from 25 to $55 \%$ by the end of the course.

$376 \quad$ Future studies should investigate if and to what degrees the intersection of active learning

377 and culturally-situated learning influences minoritized students' perception of and interest in

378 pursuing Geoscience. We recommend increasing our sample size, adjusting Collectivist

379 pedagogy to more closely resonate with minoritized students' upbringing, culture, and life

380 experience, and testing whether Collectivist pedagogy is beneficial to other students that identify

381 with high-context lifestyles (e.g., women and Indigenous people). By teaching in ways that better

382 resemble minoritized students' cultures, Geoscience can make incremental steps to improving

383 belonging, accessibility, justice, equity, diversity, and inclusivity (Be A JEDI).

\section{ACKNOWLEDGMENTS}

385 This work was supported by the National Science Foundation I-USE GeoPaths Program (NSF-

386 IUSE-1540608) awarded to Katherine Ellins. Partial writing of the manuscript was supported by 
the National Science Foundation (NSF) Grant No. ICER \#1946891. The authors thank

GeoFORCE for financial support for teaching, and Drs. Katherine Ellins, Dana Thomas, Leah

Turner, and Nicholas Soltis for stimulating discussions on this research. The authors are solely

responsible for the content of the manuscript. It does not necessarily represent the views of the

391 National Science Foundation nor GeoFORCE Texas. The authors disclose no competing

392 interests.

\section{REFERENCES}

394

395

396

397

398

399

400

401

402

403

404

405

406

407

408

409

410

411

412

413

414

415

416

417

418

419

420

421

422

423

424

425

426

427
Apple, J., Lemus, J., \& Semken, S. (2014). Teaching geoscience in the context of culture and place. Taylor \& Francis.

Astin, A. W. (1984). Student involvement: A developmental theory for higher education. Journal of college student personnel, 25(4), 297-308.

Astin, A. W. (1991). Assessment for excellence. New York: Macmillan.

Baber, L. D., Pifer, M. J., Colbeck, C., \& Furman, T. (2010). Increasing diversity in the geosciences: Recruitment programs and student self-efficacy. Journal of Geoscience Education, 58(1), 32-42.

Bernard, R. E., \& Cooperdock, E. H. (2018). No progress on diversity in 40 years.

Boyle, A., Maguire, S., Martin, A., Milsom, C., Nash, R., Rawlinson, S., ... Conchie, S. (2007). Fieldwork is good: The student perception and the affective domain. Journal of Geography in Higher Education, 31(2), 299-317.

Bransford, J. (2017). What is the STAR Legacy Cycle? IRIS Center, Vanderbilt Peabody College, available at the https://iris.peabody.vanderbilt.edu/module/hpl/cresource/q2/p07/, accessed 24 October 2017

Brown, J. S., Collins, A., \& Duguid, P. (1989). Situated cognition and the culture of learning. Educational researcher, 18(1), 32-42.

Callahan, C. N., LaDue, N. D., Baber, L. D., Sexton, J., van der Hoeven Kraft, K. J., \& Zamani-Gallaher, E. M. (2017). Theoretical perspectives on increasing recruitment and retention of underrepresented students in the geosciences. Journal of Geoscience Education, 65(4), 563-576.

Carrick, T. L., Miller, K. C., Hagedorn, E. A., Smith-Konter, B. R., \& Velasco, A. A. (2016). Pathways to the geosciences summer high school program: A ten-year evaluation. Journal of Geoscience Education, 64(1), 87-97.

Chávez, A. F., \& Longerbeam, S. D. (2016). Teaching across cultural strengths: A guide to balancing integrated and individuated cultural frameworks in college teaching. Stylus Publishing, LLC. 
Elkins, J. T., \& Elkins, N. M. (2007). Teaching geology in the field: Significant geoscience concept gains in entirely field-based introductory geology courses. Journal of Geoscience Education, 55(2), 126-132.

Ellins, K., Thomas, D. L., Campos, D., George, S. W., Goldfarb, E., Kotowski, A., ... \& Wright, V. (2018, November). USING THE STAR LEGACY CYCLE TO PROMOTE STUDENT-CENTERED FIELD LEARNING IN GEOFORCE AND STEMFORCE 12TH GRADE SUMMER ACADEMIES. In GSA Annual Meeting in Indianapolis, Indiana, USA-2018. GSA.

GeoFORCE. (2017). Annual report 2017. Available online at:

https://issuu.com/geoforcenextgeneration/docs/2017geoforcetexasannualreport.

Graham, M. J., Frederick, J., Byars-Winston, A., Hunter, A.-B., \& Handelsman, J. (2013). Increasing persistence of college students in stem. Science, 341(6153), 1455-1456.

Gudykunst, W. B., Matsumoto, Y., Ting-Toomey, S., Nishida, T., Kim, K., \& Heyman, S. (1996). The influence of cultural individualism-collectivism, self construals, and individual values on communication styles across cultures. Human communication research, 22(4), 510-543.

Hall, E. T. (1989). Beyond culture. Anchor.

Hanks, C. L., Wartes, D., Levine, R., Gonzalez, R., Fowell, S., \& Owens, G. (2007). Introducing the geosciences to Alaska natives via the rural Alaska honors institute (RAHI). Journal of Geoscience Education, 55(6), 507-513.

Houser, C., Garcia, S., \& Torres, J. (2015). Effectiveness of geosciences exploration summer program (GEOX) for increasing awareness and knowledge of geosciences. Journal of Geoscience Education, 63(2), 116-126.

Huntoon, J. E., \& Lane, M. J. (2007). Diversity in the geosciences and successful strategies for increasing diversity. Journal of Geoscience Education, 55(6), 447-457.

Ibarra, R. A. (1999). Multicontextuality: A new perspective on minority underrepresentation in sem academic fields. Making Strides, 1(3), 1-9.

Ibarra, R. A. (2001). Beyond affirmative action: Reframing the context of higher education. Univ of Wisconsin Press.

Johnson, D. R., Soldner, M., Leonard, J. B., Alvarez, P., Inkelas, K. K., Rowan-Kenyon, H. T., \& Longerbeam, S. D. (2007). Examining sense of belonging among first year undergraduates from different racial/ethnic groups. Journal of College Student Development, 48(5), 525-542.

Kotowski, A. J., Wright, V., Soltis, N., \& Ellins, K. (2018, December). Engaging high school students from underrepresented minorities in the geosciences through graduate student-led, challenge-based learning. In AGU Fall Meeting Abstracts (Vol. 2018, pp. ED12A-04).

Lave, J., Wenger, E., et al. (1991). Situated learning: Legitimate peripheral participation. Cambridge university press.

Lee, O., \& Fradd, S. H. (1998). Science for all, including students from non-english-language backgrounds. Educational researcher, 27(4), 12-21. 
Levine, R., Gonzalez, R., Cole, S., Fuhrman, M., \& Le Floch, K. C. (2007). The geoscience pipeline: A conceptual framework. Journal of Geoscience Education, 55(6), 458-468.

Libarkin, J. C., \& Kurdziel, J. P. (2002). Research methodologies in science education: Qualitative data. Journal of Geoscience Education, 50(2), 195-200.

Miller, K. C., Carrick, T., Martınez-Sussmann, C., Levine, R., Andronicos, C. L., \& Langford, R. P. (2007). Effectiveness of a summer experience for inspiring interest in geoscience among hispanic-american high school students. Journal of Geoscience Education, 55(6), 596-603.

Moore, M. Z. (2020). Fostering a sense of belonging using a multicontext approach. Journal of College Student Retention: Research, Theory \& Practice, 1521025120944828.

Pandya, R. E., Henderson, S., Anthes, R. A., \& Johnson, R. M. (2007). Best practices for broadening participation in the geosciences: strategies from the ucar significant opportunities in atmospheric research and science (soars $\left.{ }^{\circledR}\right)$ program. Journal of Geoscience Education, 55(6), 500-506.

Riggs, E. M., \& Alexander, C. J. (2007). Broadening participation in the earth sciences. Journal of Geoscience Education, 55(6), 445.

Semken, S. (2005). Sense of place and place-based introductory geoscience teaching for american indian and alaska native undergraduates. Journal of Geoscience Education, 53(2), 149-157.

Semken, S., Ward, E. G., Moosavi, S., \& Chinn, P. W. (2017). Place-based education in geoscience: Theory, research, practice, and assessment. Journal of Geoscience Education, 65(4), 542-562.

Seymour, E., \& Hewitt, N. M. (1997). Talking about leaving. Westview Press, Boulder, CO.

Sherman-Morris, K., \& McNeal, K. S. (2016). Understanding perceptions of the geosciences among minority and nonminority undergraduate students. Journal of Geoscience Education, 64(2), 147156.

Sidder, A. (2017). Geosciences make modest gains but still struggle with diversity. Eos, 98(7).

Tewksbury, B. J. (1995). Connecting the geology of Africa with the prehistoric, historical, political, and economic evolution of the continent as a strategy for teaching introductory geology and attracting minority students to geology. Journal of Geological Education, 43(5), 492-496.

Thomas, D. L., Ellins, K., Campos, D., George, S. W., Goldfarb, E., Kim, W., ... \& Wright, V. (2018, November). STUDENT EXPLORATION OF GEOSCIENCE CAREERS THROUGH CHALLENGE-BASED FIELD LEARNING IN GEOFORCE AND STEMFORCE 12 TH GRADE SUMMER ACADEMIES. In GSA Annual Meeting in Indianapolis, Indiana, USA2018. GSA.

Tsui, L. (2007). Effective strategies to increase diversity in stem fields: A review of the research literature. The Journal of Negro Education, 555-581.

Unsworth, S., Riggs, E. M., \& Chavez, M. (2012). Creating pathways toward geoscience education for native american youth: The importance of cultural relevance and self concept. Journal of Geoscience Education, 60(4), 384-392. 
Wechsler, S. P., Whitney, D. J., Ambos, E. L., Rodrigue, C. M., Lee, C. T., Behl, R. J., ... Holk, G. (2005). Enhancing diversity in the geosciences. Journal of Geography, 104(4), 141-149.

Weissmann, G. S., Ibarra, R. A., Howland-Davis, M., \& Lammey, M. V. (2019). The Multicontext path to redefining how we access and think about diversity, equity, and inclusion in stem. Journal of Geoscience Education, 67(4), 320-329.

Whitney, D. J., Behl, R. J., Ambos, E. L., Francis, R. D., Holk, G., Larson, D. O., ... Wechsler, S. P. (2005). Ethnic differences in geoscience attitudes of college students. Eos, Transactions American Geophysical Union, 86(30), 277-279.

Wolfe, B. A., \& Riggs, E. M. (2017). Macrosystem analysis of programs and strategies to increase underrepresented populations in the geosciences. Journal of Geoscience Education, 65(4), 577593.

\section{Figure and Table Captions}

Figure 1. Combined student demographics from eleventh- and twelfth-grade GeoFORCE Academies. From left to right, pie charts show a break-down of student gender identity, ethnicity, and proportions of first-generation college students (i.e., students who do not have at least one parent that received a 4-year college degree).

Figure 2. Schematic illustrations of contrasting instructional styles. (A) The eleventh-grade course used a 'slow release' approach that gradually transitioned from traditional individual learning (e.g., lectures) to active group learning (e.g., workshops and field challenges) through time. (B) The twelfth-grade course used a modified STAR Legacy Cycle; the entire course revolves around an overarching week-long challenge and embeds smaller blended learning cycles (i.e., lectures, workshops, and mini-challenges) throughout the week (Ellins et al., 2018).

Figure 3. (A) Student learning preferences from pre- and post-course surveys (light and dark grey, respectively). White circles are result averages, and error bars are 1-sigma standard deviations. (B) Self-assessed student learning experiences from activity-specific surveys. Data points are averages of 25-40 individual student survey responses. The $r^{2}$ values are provided for all data $\left(\mathrm{r}^{2}\right)$, individual activities only $\left(\mathrm{r}_{\mathrm{i}}^{2}\right)$, and group activities only $\left(\mathrm{r}_{\mathrm{g}}{ }^{2}\right)$. See text for a discussion of results. AC11: eleventh-grade academy; AC12: twelfth-grade academy.

Figure 4. Word clouds depicting students' perception of a "geoscientist's job description." The word sizes scale with the number of times it appeared in student responses, reflecting emergent themes and common perceptions. The same data are shown in Table 2.

Figure 5. Evolution of student interest in pursuing STEM and Geoscience college degrees from pre- and post-trip surveys. Note that in the post-trip surveys, 'unsure' was not provided as an option.

Figure 6. Venn Diagram illustrating the ideal environment to engage diverse students in STEM and Geoscience courses is to blend active-learning and culturally-situated learning in the classroom and field. 
577 Table 1: Selected pre-trip, post-trip, and activity-specific survey questions and prompts. Results 578 of these questions are presented and discussed in this study. The type of data acquired for each 579 question or prompt is shown in the left column (i.e., numerical data on a Likert scale, where 10 is 580 most strongly agree or prefer; Yes/No/I don't know; free response). For a full list of pre- and 581 post-trip survey questions, please see the Appendix.

583 Table 2: Word count from pre- and post-trip survey prompt: "a geoscientist's job description." 584 Data are plotted in word clouds in Figure 4. 


\section{Student Demographics $(n=65)$}

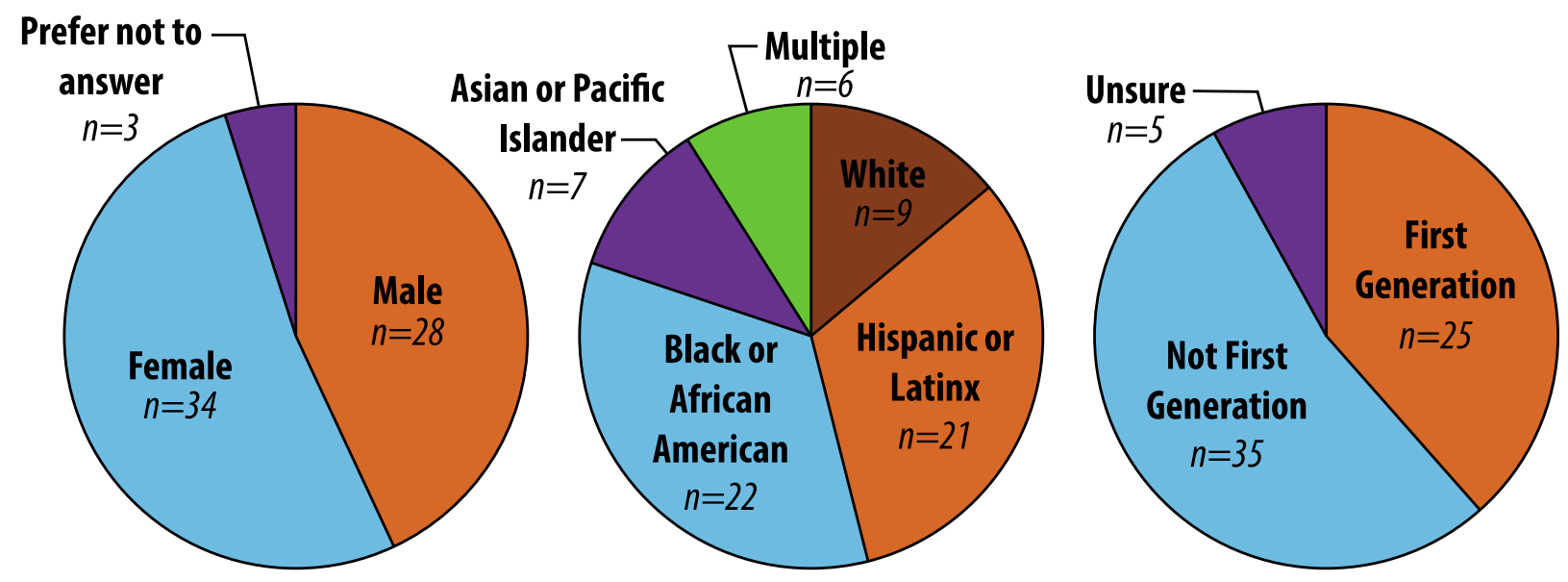

Figure 1 


\section{A Blended 'Slow Release' Approach (GF11)}

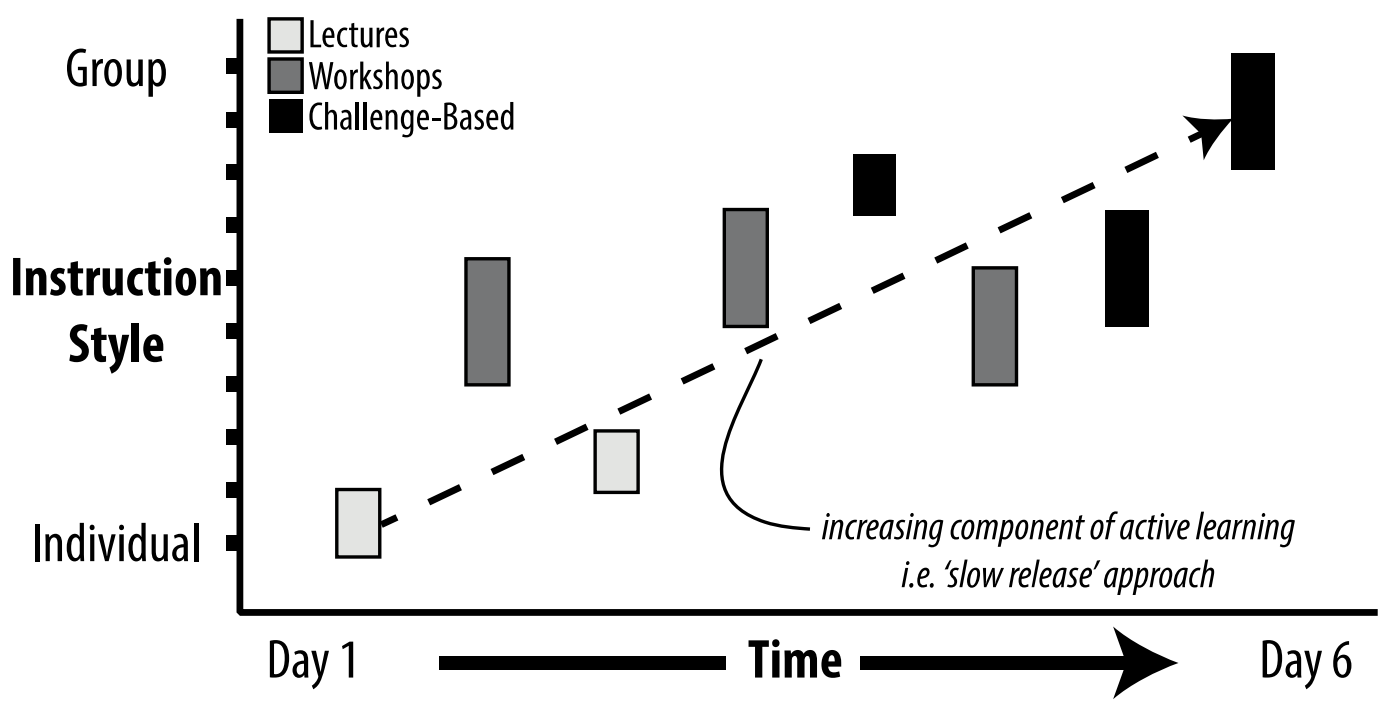

B Modified STAR Legacy Cycle (GF12)

\section{The Challenge}

Present students with a week-long goal with clear societal relevance

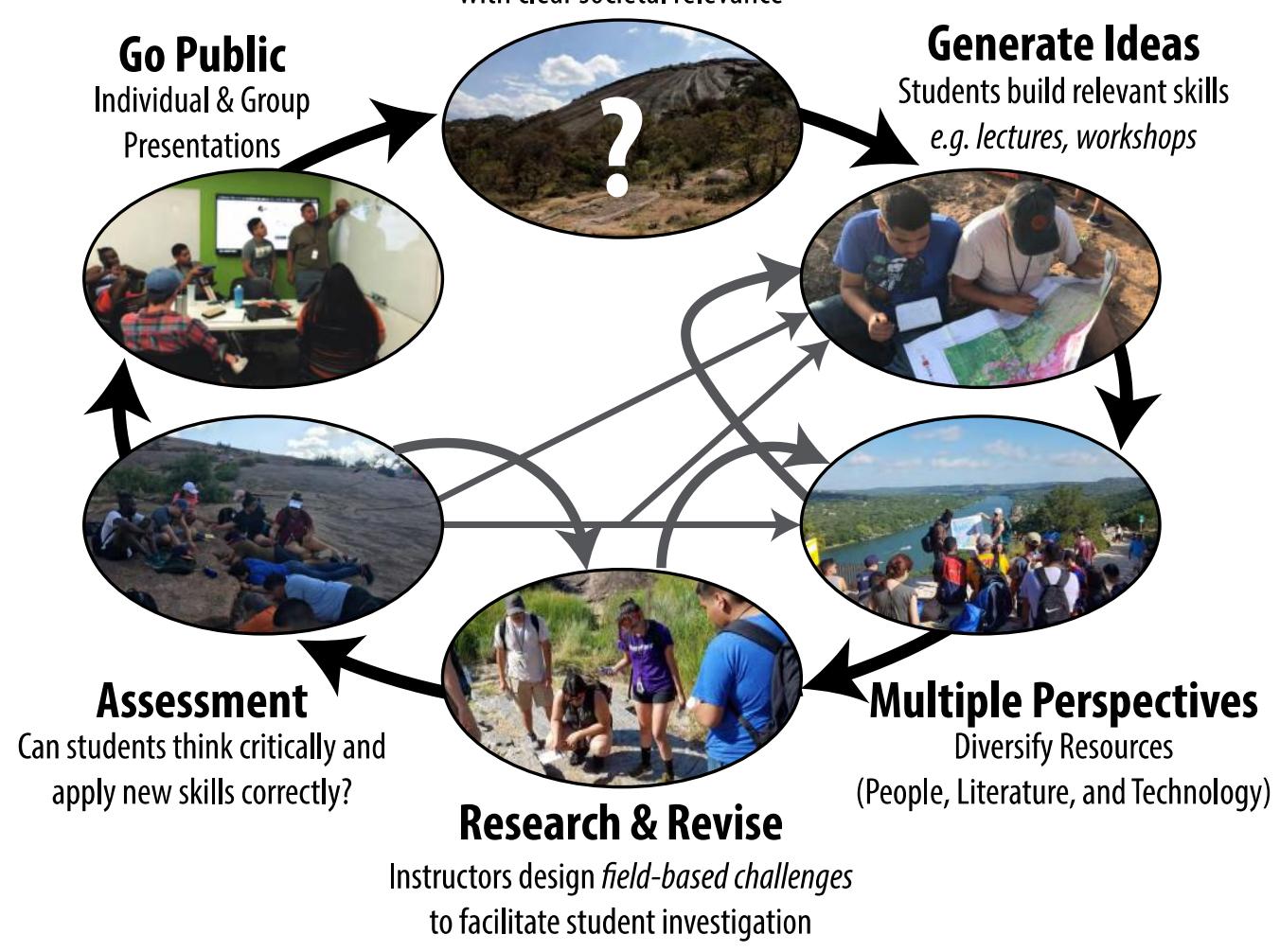

Figure 2 

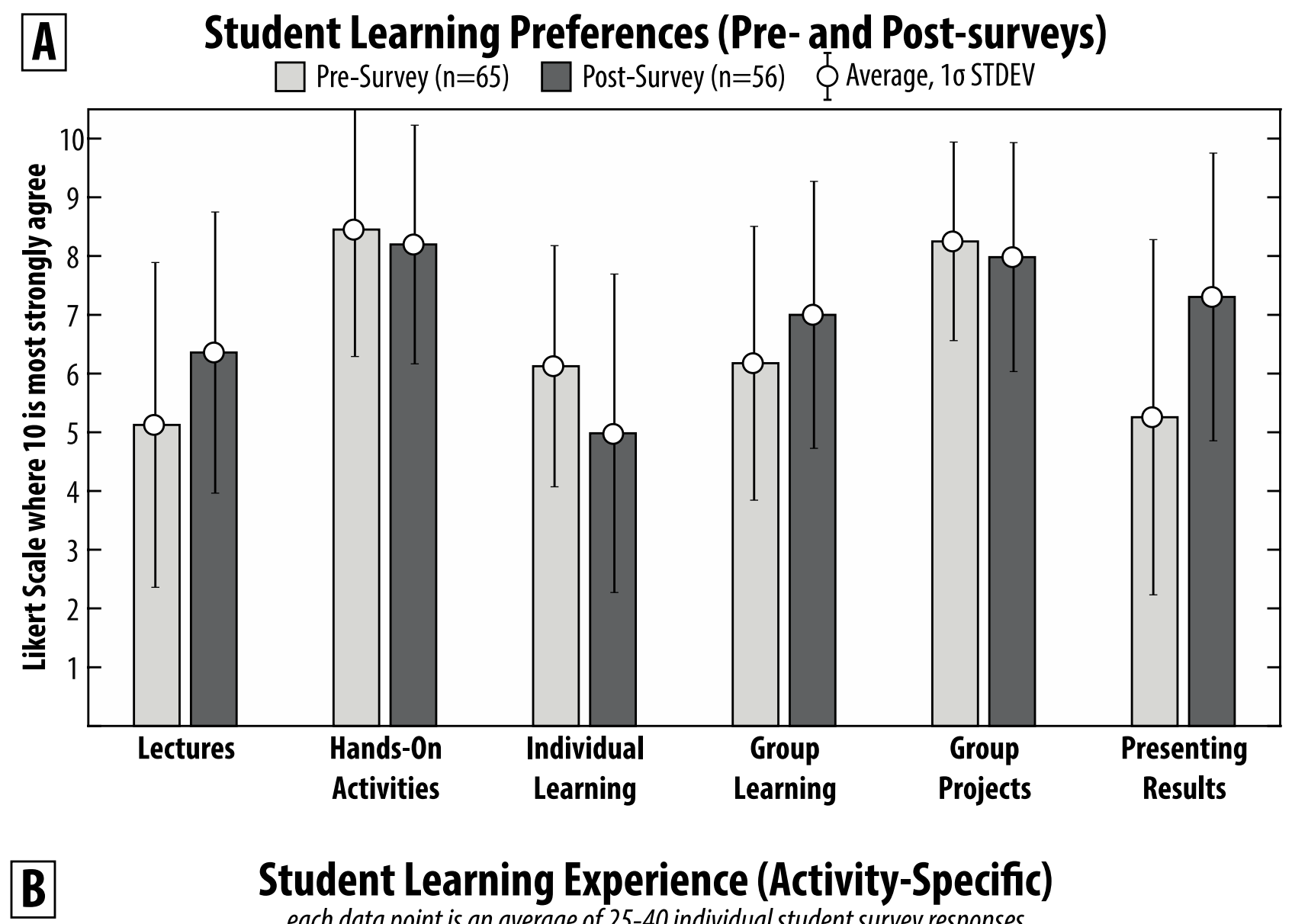

Student Learning Experience (Activity-Specific)

each data point is an average of 25-40 individual student survey responses
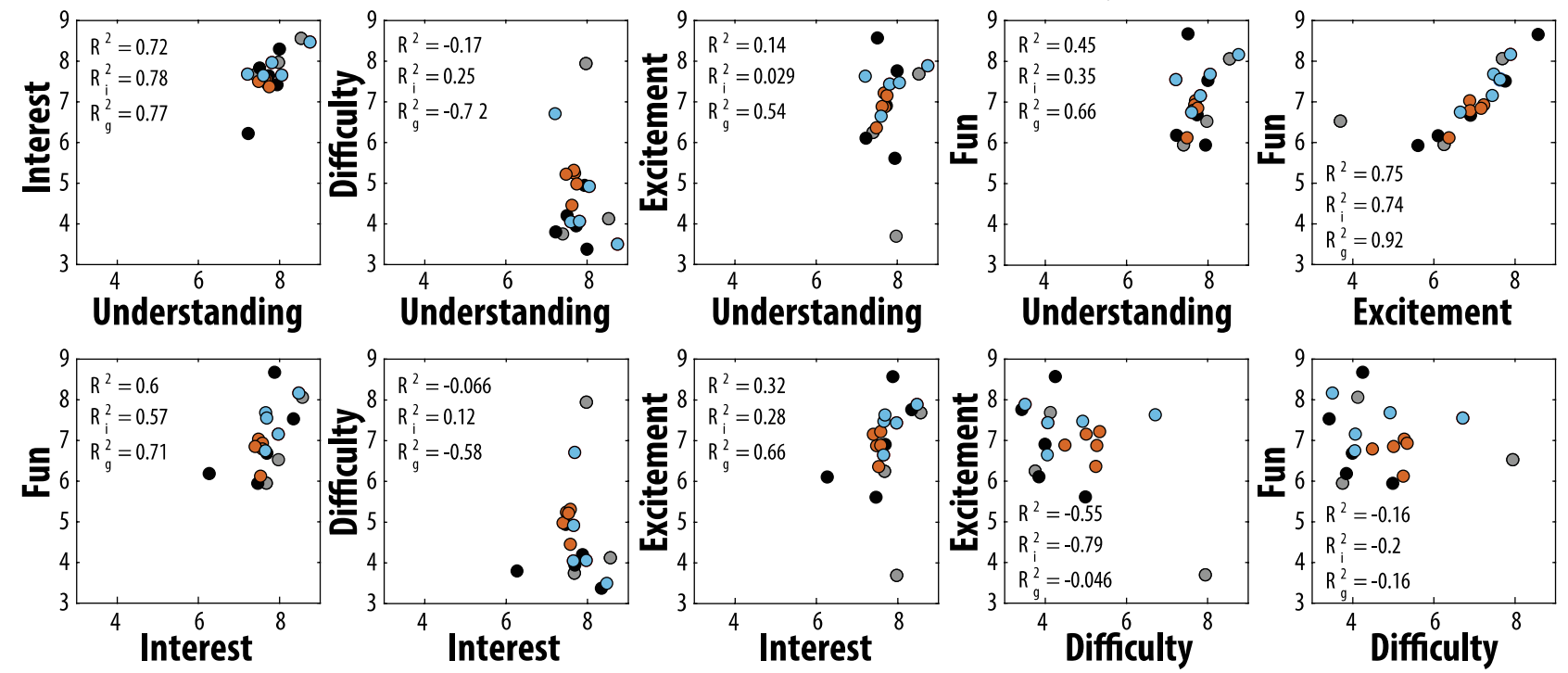

AC11: Group Learning

AC12: Group Learning

AC11: Individual Learning

AC12: Individual Learning

Figure 3 
A Pre-Trip

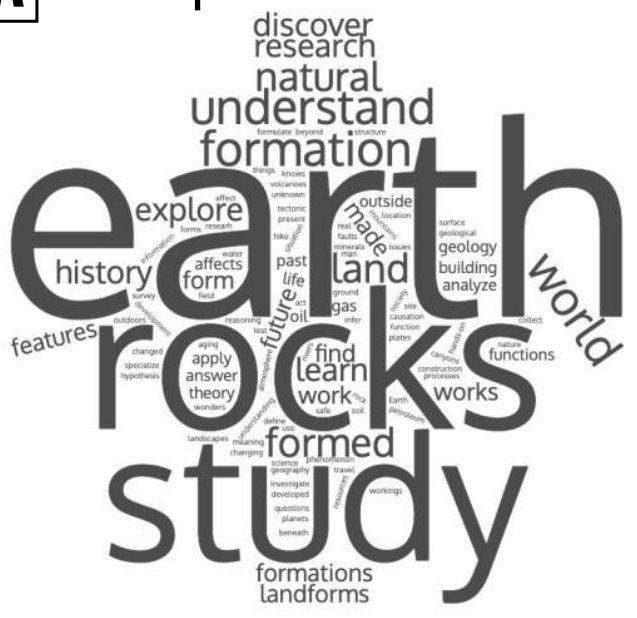

B Post-Trip

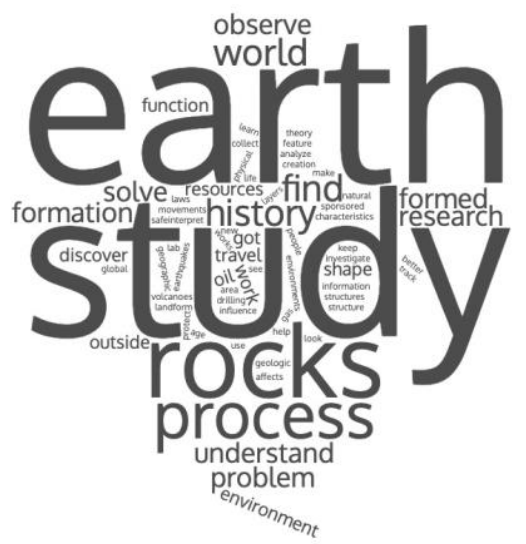

Figure 4

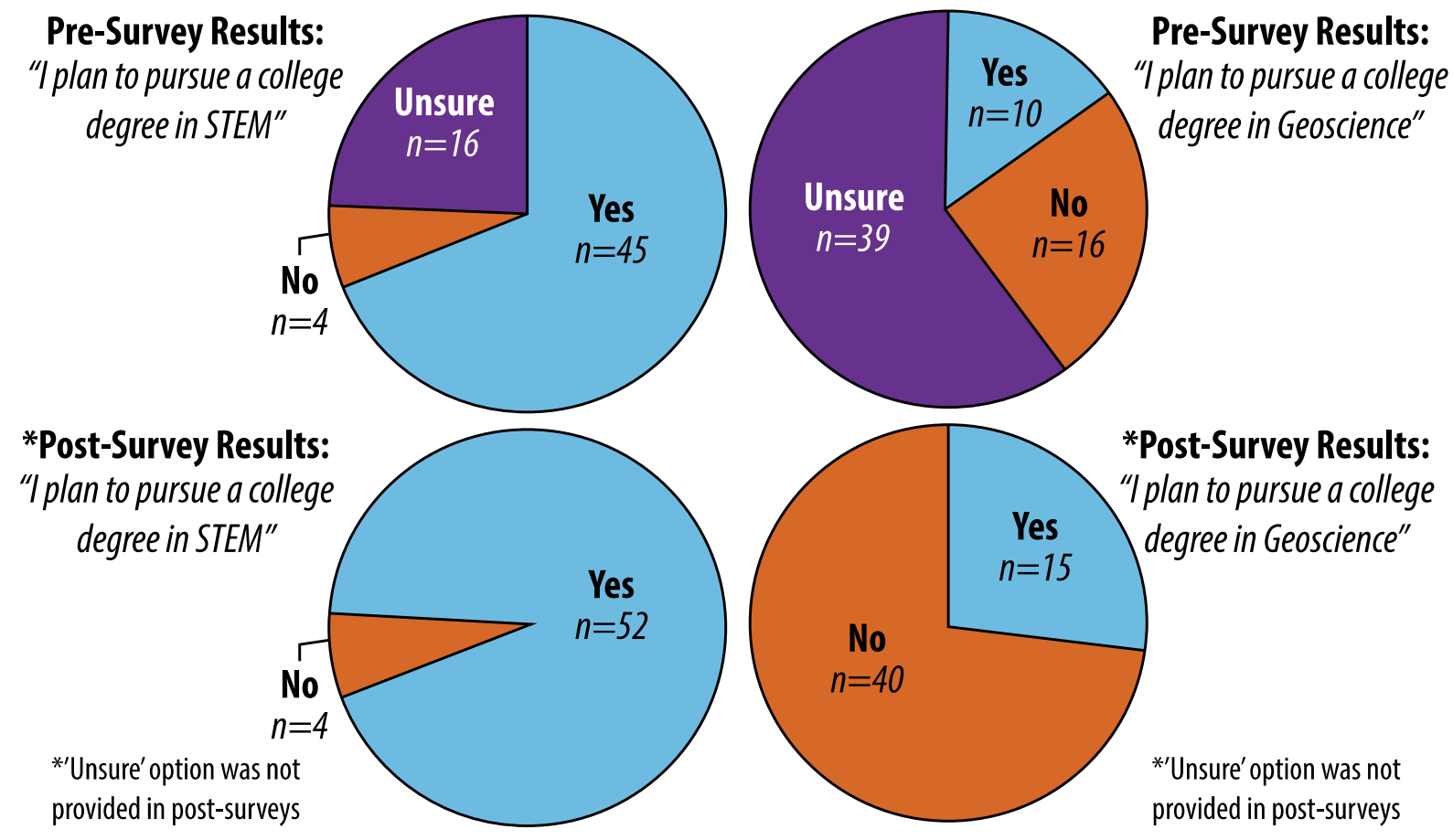

Figure 5 


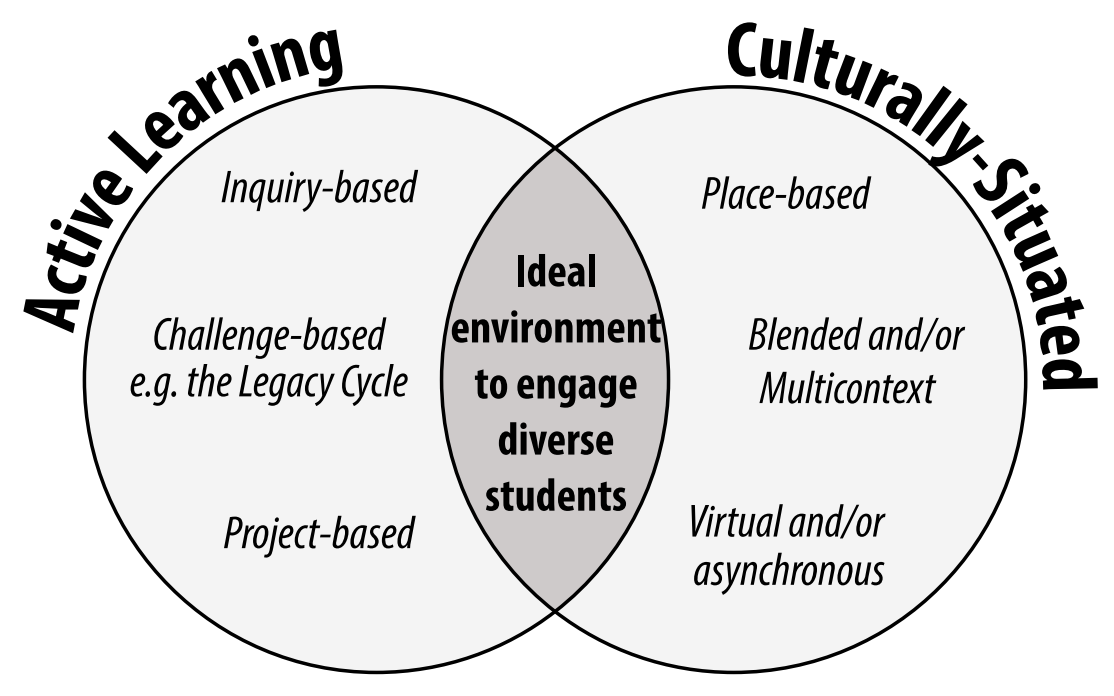

Figure 6 


\section{PRE-TRIP LEARNING PREFERENCES}

Likert 1-10

Likert 1-10

Likert 1-10

Likert 1-10

Likert 1-10

Likert 1-10

Likert 1-10

Likert 1-10

Likert 1-10

Likert 1-10

Likert 1-10

Likert 1-10

Likert 1-10

Likert 1-10
I enjoy listening to lectures.

I enjoy hands-on activities in the classroom and/or outside.

I feel like I learn the most when I listen to lectures.

I feel like I learn the most when I read textbooks.

I feel like I learn the most when I do labs and hands-on activities.

I enjoy expressing creativity in the classroom.

In general, I believe that my test and quiz scores are a good reflection of what I know and what I can do.

In general, I believe my best work is done individually.

In general, I believe my best work is done with a partner or small group.

Doing a week-long GeoFORCE project with a team of students sounds like a lot of work and I do not want to do that.

Doing a week-long GeoFORCE project with a team of students sounds fun, and I would like to do that.

I find studying for and taking quizzes and tests rewarding and fulfilling.

I find giving oral presentations and talking in front of my peers rewarding and fulfilling.

I feel like I have learned a lot from my GeoFORCE classes about how the Earth works.

\section{POST-TRIP LEARNING PREFERENCES}

Likert 1-10

Likert 1-10

Likert 1-10

Likert 1-10

Likert 1-10

Likert 1-10

Likert 1-10

Likert 1-10

Likert 1-10

Likert 1-10

Likert 1-10

Likert 1-10
This week on the GeoFORCE trip, I feel like I learned the most from listening to lectures.

This week on the GeoFORCE trip, I felt like I learned the most by doing hands-on activities in the classroom and/or outside (think of the "workshops").

This week on the GeoFORCE trip, I enjoyed activities where I had to figure things out, answer questions, and think like a scientist.

I enjoyed the evening workshops and felt prepared for the next day.

I liked evening workshops better than evening lectures.

I enjoyed giving pop-up presentations and thought it was a good way to practice talking in front of my peers and reinforce concepts we learned that day.

I think pop-up presentations are stressful.

I think pop-up presentations are a waste of time.

This past week, I feel like my best work was done individually.

This past week, I feel like my best work was done with a partner and/or a small group.

Doing a week-long GeoFORCE project with a team of students sounds like a lot of work and I do not want to do that.

Doing a week-long GeoFORCE project with a team of students sounds fun, and I would like to do that.

\section{PRE- AND POST-TRIP FUTURE PLANS AND PERCEPTIONS}

Yes/No/l don't know I plan to pursue a degree in science, technology, engineering or math. ${ }^{*}$

Yes/No/l don't know I plan to pursue a degree in the geosciences. *

Free response In three words, describe a "scientist"

Free response In a brief sentence or two, describe what a scientist does.

Free response Briefly describe your idea of a geoscientist's job description.

\section{ACTIVITY-SPECIFIC SURVEY QUESTIONS AND PROMPTS}

Free response

Free response

Likert 1-10

Likert 1-10

Likert 1-10

Likert 1-10
The main thing I had to do and/or produce today was:

Any comments?

How much do you feel like you understood the material in this activity?

Are you interested to know more about the topics in this activity?

How difficult was this activity/task?

How exciting and fun was this activity/task?

\section{Table 1}


Your version of a "Geoscientist's Job Description"

\begin{tabular}{|c|c|c|c|c|}
\hline \multicolumn{3}{|c|}{ Pre-Trip Survey } & \multicolumn{2}{|c|}{ Post-Trip Survey } \\
\hline 35 earth & 1 act & 1 phenomenon & 23 earth & 1 gas \\
\hline $25 \operatorname{rock}(s)$ & 1 affect & 1 planets & 22 study & 1 geographic \\
\hline 22 study & 1 aging & 1 plates (tectonic) & $11 \operatorname{rock}(\mathrm{s})$ & 1 geologic \\
\hline 9 formation (rock unit) & 1 atmosphere & 1 present & 7 process & $1 \mathrm{global}$ \\
\hline 6 understand & 1 beneath & 1 processes & 4 find & 1 help \\
\hline 6 world & 1 beyond & 1 questions & 4 history & 1 influence \\
\hline 6 work(s) (job) & 1 canyons & 1 real & 4 world & 1 information \\
\hline 5 formed (process) & 1 causation & 1 reasoning & 6 formation (rock unit) & 1 interpret \\
\hline 5 land & 1 changed & 1 resources & 3 formed (process) & 1 investigate \\
\hline 5 natural & 1 changing & 1 rivers & 3 observe & 1 keep \\
\hline 5 research & 1 collect & 1 safe & 3 problem (solve) & $1 \mathrm{lab}$ \\
\hline 4 discover & 1 construction & 1 science & 3 research & 1 landform \\
\hline 4 explore & 1 define & 1 site & 3 solve & 1 laws \\
\hline 4 history & 1 faults & 1 situation & 3 understand & 1 layers (rocks) \\
\hline 4 learn & 1 field & 1 society & 2 discover & 1 learn \\
\hline 3 features & 1 formulate & 1 soil & 2 environment & 1 life \\
\hline 3 find & 1 geography & 1 specialize & 2 function & 1 look \\
\hline 3 form & 1 ground & 1 structure & 2 oil & 1 make \\
\hline 3 function(s) & 1 hands-on & 1 surface & 2 outside & 1 movements \\
\hline 3 future & 1 hike & 1 survey & 2 resources & 1 natural \\
\hline 3 geology & 1 hypothesis & 1 tectonic & 2 shape (process) & 1 new \\
\hline 3 landforms & 1 infer & 1 test & 2 travel & 1 people \\
\hline 3 made & 1 information & 1 things & 2 work & 1 physical \\
\hline 2 affects & 1 investigate & 1 travel & 1 affects & 1 protect \\
\hline 2 analyze & 1 issues & 1 understanding & 1 age & 1 safe \\
\hline 2 answer & 1 knows & 1 unknown & 1 analyze & $1 \mathrm{see}$ \\
\hline 2 apply & 1 landscapes & 1 use & 1 area & 1 sponsored \\
\hline 2 building & 1 location & 1 volcanoes & 1 better & 1 structure \\
\hline 2 developed (process) & 1 man & 1 water & 1 characteristics & 1 structures \\
\hline 2 gas & 1 meaning & 1 wonders & 1 collect & 1 theory \\
\hline 2 life & 1 minerals & 1 workings & 1 creation & 1 track \\
\hline 2 oil & 1 mountains & & 1 drilling & 1 use \\
\hline 2 outside & 1 nature & & 1 earthquakes & 1 volcanoes \\
\hline 2 past & 1 outdoors & & 1 environments & 1 works \\
\hline 2 theory & 1 petroleum & & 1 feature & \\
\hline
\end{tabular}

Table 2 
What a scientist does

\begin{tabular}{|c|c|c|c|c|}
\hline \multicolumn{3}{|c|}{ Pre-Trip Survey } & \multicolumn{2}{|c|}{ Post-Trip Survey } \\
\hline 16 discover & 1 acknowledge & 1 make & 12 discover & 1 concepts \\
\hline 12 study & 1 animals & 1 matters & 12 study & 1 conduct \\
\hline 17 solve (problems) & 1 apply & 1 mystery & 16 solve (problems) & 1 draw \\
\hline 9 research & 1 approach & 1 objects & 8 research & 1 experience \\
\hline 9 world & 1 blame & 1 observe & 8 world & 1 experiments \\
\hline 8 experiment & 1 challenge & 1 opportunity & 6 earth & 1 explore \\
\hline 6 learn & 1 chemistry & 1 organisms & 6 understand & 1 facilitate \\
\hline 6 test & 1 concepts & 1 outdoors & 5 experiment & 1 hands-on \\
\hline 6 works & 1 conclusion & 1 past & 5 help & 1 hard \\
\hline 5 earth & 1 construction & 1 people & 4 environment & 1 history \\
\hline 5 explore & 1 data & 1 perform & 4 explain & 1 identify \\
\hline 4 find & 1 dedicate & 1 produce & 4 learn & 1 inferences \\
\hline 4 problems & 1 environment & 1 prove & 4 unknown & 1 knowledge \\
\hline 4 question & 1 equations & 1 reflect & 3 observe & 1 laws \\
\hline 4 theory & 1 evaluate & 1 repeat & 3 people & 1 learning \\
\hline 3 analyze & 1 experience & 1 save & 3 theory & 1 lives \\
\hline 3 answers & 1 explain & 1 sees & 2 analyze & 1 never \\
\hline 3 conduct & 1 explanation & 1 share & 2 apply & 1 observations \\
\hline 3 help & 1 figure & 1 society & 2 data & 1 occurrences \\
\hline 3 improve & 1 future & 1 specialize & 2 figure & 1 place \\
\hline 3 lives & 1 gas & 1 studies & 2 improve & 1 processes \\
\hline 3 natural & 1 god & 1 teach & 2 information & 1 prove \\
\hline 3 nature & 1 hands-on & 1 technology & 2 investigate & 1 question \\
\hline 3 understand & 1 health & 1 tendencies & 2 natural & 1 questions \\
\hline 3 work & 1 hypothesize & 1 tests & 2 nature & 1 rocks \\
\hline 2 answer & 1 identify & 1 theories & 2 process & 1 save \\
\hline 2 better & 1 indoors & 1 thinking & 2 reasoning & 1 solutions \\
\hline 2 create & 1 inhabitants & 1 universe & 2 test & 1 stop \\
\hline 2 develop & 1 insight & 1 unravel & 2 time & 1 sustainable \\
\hline 2 hypothesis & 1 interact & & 1 acknowledge & 1 topic \\
\hline 2 ideas & 1 knowledge & & 1 affect & 1 trial \\
\hline 2 laws & $1 \mathrm{lab}$ & & 1 ask & 1 uncover \\
\hline 2 phenomenon & 1 life & & 1 behind & 1 understanding \\
\hline 2 questions & 1 living & & 1 better & 1 use \\
\hline 2 science & 1 logic & & 1 break & 1 utilize \\
\hline 2 unknown & 1 logical & & $\begin{array}{l}1 \text { build } \\
1 \text { comprehend }\end{array}$ & 1 work \\
\hline
\end{tabular}

\section{Supplemental Table X}

